\title{
Extracorporeal membrane oxygenation in urgent and elective percutaneous coronary intervention
}

\author{
David Gobić*, \\ Igor Medved, \\ Vjekoslav Tomulić, \\ Sandro Brusich, \\ Kristian Deša, \\ Luka Zaputović \\ University of Rijeka School \\ of Medicine, University \\ Hospital Centre Rijeka, \\ Rijeka, Croatia
}

KEYWORDS: coronary artery disease, percutaneous coronary intervention, extracorporeal membrane oxygenation.

CITATION: Cardiol Croat. 2016;11(3-4):99. | DOI: http://dx.doi.org/10.15836/ccar2016.99

*ADDRESS FOR CORRESPONDENCE: David Gobić, Klinički bolnički centar Rijeka, T. Strižića 3, HR-51000 Rijeka, Croatia. / Phone: +385-91-508-6868 / E-mail: dgobic@gmail.com

ORCID: David Gobić, http://orcid.org/0000-0001-9406-1127 • Igor Medved, http://orcid.org/0000-0002-2029-200X Vjekoslav Tomulić, http://orcid.org/0000-0002-3749-5559 • Sandro Brusich, http://orcid.org/0000-0001-7394-6698 Kristian Deša, http://orcid.org/0000-0002-2068-7984 • Luka Zaputović, http://orcid.org/0000-0001-9415-9618

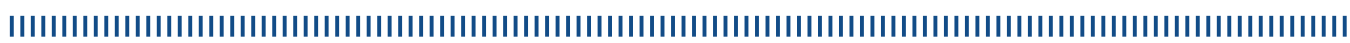

Introduction: Extracorporeal membrane oxygenation (ECMO) is basically a heart-lung machine and an ECMO system consists of a pump and an oxygenator. The oxygenator and pump are integrated into a closed circuit to prevent any contact between the blood and air. All the components of ECMO are mounted on a portable/mobile console positioned near the patient's bed. These enable ECMO patients to be taken to a cardiac catheter laboratory where ECMO is used to support patients undergoing highrisk percutaneous coronary intervention (PCI). Veno-arterial ECMO (VA ECMO) is indicated for patients with myocardial pump failure and can also support lung failure at the same time. Peripheral cannulation is preferred since cannulation should be as simple as possible and require the least possible surgical intervention. Drainage is carried out via a femoral vein and arterial cannulation is possible on a femoral artery or a subclavian artery. Myocardial pump failure defined as a cardiac index $<2.0 \mathrm{~L} / \mathrm{min} /$ $\mathrm{m}^{2}$ is generally regarded as the criterion for mechanical circulatory support. This is a good indication for the use of VA ECMO in patients who are refractory to treatment with medication. It seems that PCI supported by VA ECMO is indicated for potentially reversible myocardial damage, for example patients in cardiogenic shock in acute myocardial infarction, and for high-risk PCI patients..$^{1-3}$

Patients and Methods: Clinical characteristics of patients supported by ECMO during the high risk urgent or elective PCI in University Hospital Centre Rijeka are analyzed using available medical records. Results: During the 6 months period 8 patients who have undergone an urgent or elective PCI were supported by ECMO. Survival rate was $75 \%$. The shortest ECMO support was performed for 45 minutes and longest for 356 hours and 25 minutes.

Conclusion: Clearly defined and accepted indications for ECMO are still lacking and they are often derived from local institutional experience. More experience leads to more liberal indication and more successful results.
RECEIVED:

February 10, 2016

ACCEPTED:

February 20, 2016

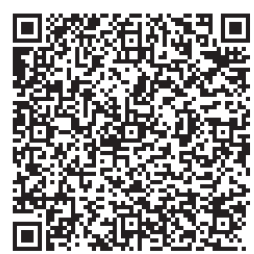

LITERATURE IIIIIIIIIIIIIIIIIIIIIIIIIIIIIIIIIIIIIIIIIIIIIIIIIIIIIIIIIIIIIIIIIIIIIIIIIIIIIIIIIIIIIIIIIIIIIIIIIIIIIIIIIIIIII

1. Schmid C, Philipp A. Extracorporeal Membrane Oxygenation (ECMO). In: Schmid C, Philipp A, editors. Guidelines for Extracorporeal Circulation. Heidelberg: Springer Medizin; 2011. p. 84-95.

2. Tsao NW, Shih CM, Yeh JS, Kao YT, Hsieh MH, Ou KL, et al. Extracorporeal membrane oxygenation-assisted primary percutaneous coronary intervention may improve survival of patients with acute myocardial infarction complicated by profound cardiogenic shock. J Crit Care. 2012 Oct;27(5):530.e1-11. DOI: http://dx.doi.org/10.1016/j.jcrc.2012.02.012

3. Sung WC, Jin KJ, Sung SK, Seung HK. Long-term clinical outcome of patients with AMI complicated by cardiogenic shock or cardiac arrest who received extracorporeal membrane oxygenation assisted primary PCI. J Am Coll Cardiol. 2015;65(10_S):. DOI: http://dx.doi.org/10.1016/S0735-1097(15)61944-1 